\title{
Free lunch is a good thing for children
}

$\mathrm{T}$ he plate of food in the picture looked more like something you would see in a fancy restaurant than in a school cafeteria. Yet this was indeed a lunch for a school child. A lunch that was hot, balanced and nutritious. What's more, it is free for every student, regardless of their family's financial situation. The only catch: you have to live in Sweden.

Sweden's school lunch program, enshrined in the country's Education Act in 1997, was viewed with envy by many attending a session called "School Food: Hungry to Learn" on Nov. 25 at the Championing Public Health Nutrition conference, held by the Centre for Science in the Public Interest in Gatineau, Quebec.

Though the quality of the free meals varies across the country, the food is generally fresh. No packets, no cartons, no cans. It is served on proper plates with proper cutlery. In most schools, there are no soft drinks or desserts. And the teachers in the cafeteria are not there to monitor the children, but rather to join them.

"The school meal should be an integrated part of the school day, a time for relaxation, a time for regeneration, a time for a nice meal in a nice environment so that you are able to learn for the rest of the day," said Emma Patterson, a panelist at the session and project manager for SkolmatSverige.se, a web-based system in Sweden that helps schools evaluate the quality of the lunches they provide.

Fellow panelist Member of Parliament (Etobicoke North), Kirsty Duncan, painted a very different picture for Canada. Hundreds of thousands of Canadian children rely on food banks, she said. Many struggle to meet their

suggested Duncan, who said that Canada needs a comprehensive school nutrition program.

"Ensuring every child can develop to his or her full potential should be everyone's concern," said Duncan.

Indeed, school food should be a fundamental building block of a wider national food strategy, said Diana Bronson, executive director of Food Secure Canada, an alliance of organizations and individuals working to advance food security and sovereignty.

"Even if we don't agree on many other things, it is obvious and essential to recognize the importance of kids eating well in school," said Bronson.

In Canada, however, most programs that provide meals to hungry students rely on charities, noted Bronson. There has been no national assessment of these programs. Nobody has established best practices or fig-

basic nutritional needs, and far too many go to school without breakfast.

According to Food Banks Canada, nearly 850000 Canadians rely on food banks every month, and $36 \%$ of those helped are children and youth.

"I think it is absolutely abhorrent that any child would go to school hungry in a country as wealthy as Canada, and that our country is one of the only developed countries without a student nutrition program," said Duncan.

It is well known, Duncan noted, that hunger affects a child's behaviour. It affects concentration, creativity and problem-solving. A nutritious diet, on the other hand, reduces absenteeism while improving grades and graduation rates. Providing meals to students should be seen as an investment, not a cost, ured out if a model like Sweden's lunch program would work in Canada or if something different is needed.

Bronson did suggest, though, that a school food program in Canada should be universal, like the health care system. It is not true, she noted, that only children from low-income families go to school hungry. A child from a busy middle-class home with two working parents may also often go without breakfast. A universal system also reduces the stigma of accepting free meals.

"But above all," said Bronson, "the reason we need a universal program is because food is a human right." Roger Colllier, CMAJ

CMAJ 2015. DOI:10.1503/cmaj.109-4952 